\title{
BURNOUT SYNDROME AMONG HEALTHCARE PROVIDERS IN DIFFERENT HOSPITALS IN MINIA CITY
}

\author{
By \\ Abd EL Latief OK ${ }^{1}$, Mahfouz EM ${ }^{2}$, Ewis $\mathrm{AA}^{2}$ and Seedhom AE ${ }^{2}$ \\ ${ }^{I}$ Department of Public Health and Occupational Medicine, ${ }^{2}$ Department of Public Health and Preventive \\ Medicine, Faculty of Medicine, Minia University.
}

\begin{abstract}
Introduction: Burnout is an occupational physical, physiological and psychological stress reaction syndrome caused by chronic exposure to job-related stressors; and characterized by Emotional Exhaustions (EE), Depersonalization (DP), and a low sense of Personal Accomplishment (PA).Health-care providers (HCPs) are particularly vulnerable and prone to burnout syndrome (BOS). Aim of work: To estimate frequency and recognize risk indicators for BOS among HCPs in Minia city. Materials and methods: A total of 280 hospital workers from three different hospitals in Minia city completed a self-administered questionnaire that was used to measure BOS. Data was collected using Maslach Burnout Inventory (MBI). Results: Health care providers reported high levels of EE (61.8\%), high levels of DP (52.5\%) and low levels of PA $(45.7 \%)$. Surgical department's HCPs showed the highest score of burnout in EE level, however those in emergency department recorded the highest level in both (DP) and (PA). The 3 subscales were high among those with longer duration at work. Using logistic regression, the most significant predictors of $\mathrm{EE}$ were found to be gender followed by years of working, and smoking status. Factors associated with DP were years of working followed by age, hours of working shift, and with PA were age followed by sleeping time, and gender. Conclusion: Health care providers are highly vulnerable to each of the dimensions of Burnout syndrome - namely emotional exhaustion, depersonalization, and personal accomplishment- in the hospital work. Decreasing BOS by incorporation of mindfulness and teamwork into practice, decrease stress from electronic health records, promote physician control of the work environment, and to find balance in life.
\end{abstract}

Key words: Emotional exhaustion, Depersonalization, Personal Accomplishment, Burnout and Maslach inventory. 


\section{Introduction}

By virtue of their profession, health care providers are particularly a vulnerable group for experiencing burnout syndrome (BOS). They are exposed to high levels of stress while practicing their profession. The extent of burnout may vary depending on the specialty, setting and work environment. Understanding dynamic risk factors associated with burnout may help to develop strategies for preventing and treating burnout. Prevalence of BOS varies between countries, across time and specialties. This variation is well understood and expected as burnout is related to stressors arising from work environment and the latter is influenced by these variables. BOS is a psychological term (concept) for the experience of long-term exhaustion and diminished interest (depersonalization or cynicism), usually in the work context (McGrath et al., 1989).

Burnout is an increasing problem among the medical staff, it is highly prevalent among the health care workers, and is associated with difficult working conditions and feelings of dissatisfaction at work (De Oliveira et al., 2010).

BOS is specific to the work context in contrast with depression, which concerns professional and private life. BOS has three dimensions: Emotional Exhaustion, Depersonalization (or cynicism) and a sense of low personal accomplishment. Emotional Exhaustion is the key component of BOS. The symptoms of burnout are nonspecific and include irritability, emotional instability, rigidity in relationships with colleagues and organic complaints such as eating problems, tiredness or sleep disorders (Maslach et al., 1986).

Several studies have been done to measure patient satisfaction with health care providers but there are little studies for measuring the satisfaction among health staff with their work especially among physicians. Most researches on burnout syndrome (BOS) have been done in developed countries and little is known about professional burnout among physicians working in Egypt.

\section{Aim of work}

To estimate frequency and recognize risk indicators for burnout syndrome among health care providers in Minia city.

\section{Materials and methods}

Study design : A hospital based cross -sectional study 
Place and duration of study: The study was conducted from October to December 2016 among physicians and nurses working in a variety of health care settings in 3 hospitals in Minia city: The General Minia Hospital, the Health Insurance Hospital and Minia University Hospital.

Study sample: A stratified random sample was taken from each hospital to include both sexes, nurses and physicians and different specialties according to their distribution in the study population and was employed at the hospital for more than 6 months and not on vacation during the study period.

The sample size was calculated using Epi Info version 2000. It was 167 health care workers at confidence level of $99.9 \%$ and those who really included, were 280 health care providers to guard against non- respondents (prevalence $12.5 \%$, population 1244 , and confidence $99.9 \%)$.

\section{Study methods:}

A predesigned questionnaire was prepared for the assessment of the determinants of burnout, and data were collected about socio-demographic variables (age, sex, residence, marital status); job characteristics and experiences (job type, department , years of experience, shifts hours, attitudes to work ( satisfaction of work environment, their income, sleeping time hours, their holidays, feeling comfortable with his/her colleagues) and health problems (diseases suffered before employment, disease acquired during work).

\section{Maslach Burnout Inventory(MBI),}

MBI first developed by Maslach et al. in 1986, was the assessment instrument used in the study. It has become the almost universally accepted gold standard to assess burnout due to its high reliability and validity. It was translated into Arabic and then back translated into English, to ensure correct translation of the questions. The Arabic version was revised by 7 experts and tested in a pilot study. The reliability of the questionnaire was tested by Cronbach alpha and found to be 0.81 . The MBI includes 22 items with a 7-point Likert-type rating scale. Items were written in the form of statements about personal feelings or attitudes. The frequency scale is labeled at each point, ranging from 0 (never) to 6 (everyday). The MBI has 3 subscales: Emotional Exhaustion (EE), which refers to both physical and mental exhaustion 
(statements no. 1-9); Depersonalization (DP), which consists of attitude changes of the individual when coming into contact with those who receive his/her services as he/she begins to display a cold and impersonal contact with suffering (statements No. 10-14); and reduced Professional Accomplishment (PA), which measures perception of the influence of the others, wellbeing with his/her work, as well as the relationship with problems, evidencing a feeling of dissatisfaction (statements No. 15-22). Burnout is conceptualized as a continuous variable, ranging from a low to average to high probability of experiencing feelings of each element of burnout. A high degree of burnout is reflected in high scores on the Emotional Exhaustion (maximum score of $\geq 30$ ) and Depersonalization subscales (maximum score of $\geq 12$ ) and in low scores on the reduced Professional Accomplishment subscale (maximum score of $\leq 33$ ). An average degree of burnout is reflected in average scores on the 3 subscales. A low degree of burnout is reflected in low scores on the Emotional Exhaustion and Depersonalization subscales and in higher scores on the reduced Professional Accomplishment subscale. Subscales were classified into low, moderate and high level of burnout according to Table I (Embriaco et al., 2007).

Table I: Classification of scores on subscales of the Maslach Burnout Inventory (MBI)

\begin{tabular}{|l|lll|}
\hline MBI subscale & \multicolumn{3}{|l|}{ Range of experienced burnout } \\
& Low & Moderate & High \\
\hline Emotional Exhaustion & $\leq 17$ & $18-29$ & $\geq 30$ \\
\hline Depersonalization & $<6$ & $6-11$ & $\geq 12$ \\
\hline Personal Accomplishment & $\geq 40$ & $39-34$ & $\leq 33$ \\
\hline
\end{tabular}

A pilot test on $10 \%$ of the subjects (whose results were included in the study) was carried out before the start of data collection 


\section{Consent}

All participants in the study gave verbal consent to participate.

\section{Ethical approval}

The study had been approved by the Ethical Committee for Human Studies in Faculty of Medicine, Minia University.

\section{Data management}

Statistical analysis of data was performed using SPSS, version 20. Chisquare test and ANOVA test were used. Also, multiple linear regression analysis was used to see the combined effect of different independent variables on the target (dependent) variable. A statistically significant level was considered when $\mathrm{p}$-value was less than 0.05 .

\section{Results}

Table 1: Socio-demographic characteristics of the studied health-care providers $(\mathrm{No}=\mathbf{2 8 0})$

\begin{tabular}{|c|c|c|}
\hline $\begin{array}{l}\text { Health-care providers } \\
\text { Physicians } \\
\text { Nurses } \\
\text { Hospital type } \\
\text { University } \\
\text { General } \\
\text { Insurance } \\
\end{array}$ & $\begin{array}{l}\text { No } \\
134 \\
146 \\
97 \\
98 \\
85\end{array}$ & $\begin{array}{c}(\%) \\
(47.8 \%) \\
(52.2 \%) \\
(34.6 \%) \\
(35 \%) \\
(30.4 \%)\end{array}$ \\
\hline $\begin{array}{ll}\text { Age } & \\
& \text { Range } \\
& \text { Mean } \pm \text { SD }\end{array}$ & \multicolumn{2}{|c|}{$\begin{array}{c}20-58 \text { years. } \\
39.45 \pm 10.30\end{array}$} \\
\hline $\begin{array}{ll}\text { Sex } & \\
& \text { Male } \\
& \text { Female }\end{array}$ & $\begin{array}{l}(44.6 \%) \\
(55.4 \%)\end{array}$ & $\begin{array}{l}125 \\
155\end{array}$ \\
\hline $\begin{array}{l}\text { Marital status } \\
\text { Single } \\
\text { Married } \\
\text { Widow, Divorced }\end{array}$ & $\begin{array}{c}(21.1 \%) \\
(73.9 \%) \\
(5 \%)\end{array}$ & $\begin{array}{c}59 \\
207 \\
14\end{array}$ \\
\hline $\begin{array}{c}\text { Residence } \\
\text { Urban } \\
\text { Rural }\end{array}$ & $\begin{array}{l}144 \\
136\end{array}$ & $\begin{array}{l}(51.2 \%) \\
(48.4 \%)\end{array}$ \\
\hline
\end{tabular}

Table 1 showed that the age of the participants ranged from 38-58 years with a mean of $39.45 \pm 10.30$ years. About $55 \%$ are females and $73.9 \%$ were married. More than half of them were from urban areas (51.2\%). 
Table 2: Frequency of the three subscales of burnout syndrome among Minia health care providers.

\begin{tabular}{|l|c|c|}
\hline BOS subscales & No & \% \\
\hline Emotional Exhaustion & & 11.4 \\
Low & 32 & 26.8 \\
Moderate & 75 & 61.8 \\
High & 173 & \\
\hline Depersonalization & & 14.6 \\
Low & 41 & 32.9 \\
Moderate & 92 & 52.5 \\
High & 147 & \\
\hline Personal Accomplishment & & 45.7 \\
Low & 128 & 28.2 \\
Moderate & 79 & 26.1 \\
High & 73 & \\
\hline
\end{tabular}

BOS: Burnout syndrome

Table 2 showed that $61.8 \%$ of respondents scored high Emotional Exhaustion and $52.2 \%$ scored high Depersonalization and a majority (45.7\% and 28.2\%) had reduced Personal Accomplishment.

Table 3: Correlation between burnout subscales and years of work among the studied sample of Minia health care providers.

\begin{tabular}{|l|c|c|}
\hline BOS subscales & $\mathbf{R}$ & $\mathbf{p}$ \\
\hline EE & .311 & $<0.05^{*}$ \\
\hline DP & .380 & $<0.05^{*}$ \\
\hline PA & .374 & $<0.05^{*}$ \\
\hline
\end{tabular}

BOS: Burnout syndrome

PA : Personal Accomplishment
EE : Emotional Exhaustion,

DP : Depersonalization

* Significant

Tables (3) showed that there was significant positive fair correlation between burnout sub-scales and years of work. 
Table 4: Burnout level among different departments and distribution of healthcare providers in relation to the 3 subscales of the Maslach among the studied sample.

\begin{tabular}{|c|c|c|c|c|c|}
\hline BOS subscales & $\begin{array}{l}\text { Medicine } \\
\text { No }(\%)\end{array}$ & $\begin{array}{l}\text { Surgery } \\
\text { No }(\%)\end{array}$ & $\begin{array}{c}\text { Emergency } \\
\text { No }(\%)\end{array}$ & $\mathbf{X}^{2}$ & $\mathbf{p}$ \\
\hline $\begin{array}{l}\text { EE } \\
\text { Low } \\
\text { Moderate } \\
\text { High }\end{array}$ & $\begin{array}{l}28(29.2 \%) \\
28(29.2 \%) \\
40(41.7 \%)\end{array}$ & $\begin{array}{c}3(3.1 \%) \\
21(21.9 \%) \\
72(75.0 \%)\end{array}$ & $\begin{array}{c}1(1.1 \%) \\
26(29.5 \%) \\
61(69.3 \%)\end{array}$ & 51.5 & $<0.001 * *$ \\
\hline $\begin{array}{l}\text { DP } \\
\text { Low } \\
\text { Moderate } \\
\text { High } \\
\end{array}$ & $\begin{array}{l}27(28.1 \%) \\
39(40.6 \%) \\
30(31.2 \%)\end{array}$ & $\begin{array}{c}7(7.3 \%) \\
33(34.4 \%) \\
56(58.3 \%) \\
\end{array}$ & $\begin{array}{c}7(8.0 \%) \\
20(22.7 \%) \\
61(69.3 \%) \\
\end{array}$ & 36.3 & $<0.001 * *$ \\
\hline $\begin{array}{l}\text { PA } \\
\text { Low } \\
\text { Moderate } \\
\text { High }\end{array}$ & $\begin{array}{l}28(29.2 \%) \\
25(26.0 \%) \\
43(44.8 \%)\end{array}$ & $\begin{array}{l}44(45.8 \%) \\
33(34.4 \%) \\
19(19.8 \%)\end{array}$ & $\begin{array}{l}56(63.6 \%) \\
21(23.9 \%) \\
11(12.5 \%)\end{array}$ & 34.5 & $<0.001 * *$ \\
\hline \multicolumn{6}{|c|}{ Health-care providers } \\
\hline & Physicians & Nurses & & $\mathbf{X}^{2}$ & p-value \\
\hline $\begin{array}{l}\text { EE } \\
\text { Low } \\
\text { Moderate } \\
\text { High } \\
\end{array}$ & $\begin{array}{c}18(13.4 \%) \\
41(30.6 \%) \\
75(56 \%)\end{array}$ & $\begin{array}{l}14(9.6 \%) \\
34(23.3 \%) \\
98(67.1 \%)\end{array}$ & & 3.7 & 0.157 \\
\hline $\begin{array}{l}\text { DP } \\
\text { Low } \\
\text { Moderate } \\
\text { High } \\
\end{array}$ & $\begin{array}{l}15(11.2 \%) \\
41(30.6 \%) \\
78(58.2 \%)\end{array}$ & $\begin{array}{l}26(17.8 \%) \\
51(34.9 \%) \\
69(47.3 \%)\end{array}$ & & 4.1 & 0.132 \\
\hline $\begin{array}{l}\text { PA } \\
\text { Low } \\
\text { Moderate } \\
\text { High }\end{array}$ & $\begin{array}{l}62(46.3 \%) \\
41(30.6 \%) \\
31(23.1 \%)\end{array}$ & $\begin{array}{l}66(45.2 \%) \\
38(26.0 \%) \\
42(28.8 \%)\end{array}$ & & 1.83 & 0.500 \\
\hline
\end{tabular}

BOS: Burnout syndrome

EE: Emotional Exhaustion,

DP: Depersonalization

PA: Personal Accomplishment

** Highly statistically significant 
Table 4 showed that health care providers in Emergency Department recorded the highest level of burnout in Depersonalization and Personal Accomplishment sub-scales (69.3\%) and (63.6\%) respectively, but in EE subscale the Surgical team was higher $(75 \%)$ than both Emergency $(69.3 \%)$ and Internal Medicine team $(41.7 \%)$. About $67.1 \%$ of nurses experienced high Emotional Exhaustion compared with $(56 \%)$ of physicians, a difference was not statistically significant $(\mathrm{P}=0.157)$. For the Depersonalization subscale, $(17.8 \%)$ of nurses had low scores and (34.9\%) moderate scores, compared with $(11.2 \%)$ and $(30.6 \%)$ of physicians respectively, and the difference was not statistically significant $(\mathrm{P}=0.132)$. About $46 \%$ of physicians experienced highly reduced feelings of Personal Accomplishment and the rate was slightly lower among nurses (45.2\%).

\section{Table (5): Multivariate linear Regression analysis of variables affecting burnout on the Maslach Burnout Inventory among the studied health-care providers.}

\begin{tabular}{|c|c|c|c|}
\hline Variables & B & t- value & p-value \\
\hline \multicolumn{4}{|l|}{$\mathbf{E E}$} \\
\hline $\begin{array}{l}\text { Sex } \\
\text { (Female) }\end{array}$ & 0.411 & 7.717 & $<0.001 * *$ \\
\hline Duration of work/ years & 0.244 & 1.697 & 0.091 \\
\hline Smoking & 0.179 & 3.503 & $<0.001 * *$ \\
\hline \multicolumn{4}{|l|}{ DP } \\
\hline Duration of work/ years & 0.218 & 1.408 & 0.160 \\
\hline Age/ years & 0.154 & 1.007 & 0.315 \\
\hline Hours of shift & 0.129 & 2.304 & $<0.05^{*}$ \\
\hline \multicolumn{4}{|l|}{ PA } \\
\hline Age/ years & 0.391 & 2.668 & $<0.05^{*}$ \\
\hline Sleeping time/ hours & 0.211 & 2.140 & $<0.001 * *$ \\
\hline $\begin{array}{l}\text { Sex } \\
\text { (Female) }\end{array}$ & 0.189 & 3.454 & $<0.001 * *$ \\
\hline
\end{tabular}

EE: Emotional Exhaustion,

DP: Depersonalization

PA: Personal Accomplishment

* Statistically significant

** Highly statistically significant 
Table (5) revealed that the factors significantly most associated with EE were sex, smoking, and the factors significantly most associated with DP were hours of shift, while factors significantly most associated with PA subscale of burnout syndrome were age followed by sleeping time, and then gender.

\section{Discussion}

The job-related burnout is increasingly a problem affecting healthcare workers, suffering from negative feelings for work, self and life (Sr̈gaard et al., 2007). Health care providers were exposed to their clients' psychological, socioeconomic and physical problems, so burnout will develop easily, especially in departments where critical care is provided (Pavlakis et al., 2010). About two-thirds of our study subjects had a high level of EE subscale, about half had a high level of DP, and slightly less than the half of subjects had high reduction in PA (Table2). This could be attributed to the overburdened healthcare system in Egypt, especially in both Surgical and Emergency sectors, that require instruments, continuous training, and working with critical ill patients. The health care system in Egypt $>$ s hospitals had several defects as lack of resources, inadequate salaries, lack of control, inadequate security, difficult work schedules with long hours of work and frequent shifts, and poor career advancement.

The overall prevalence of burnout as well as the three dimensions of BOS among doctors may vary between countries. The results of a study in Qatar that was conducted by Abdulla et al., 2011 and colleagues were lower than these results in EE and DP subscales, as $46.9 \%$ of respondents scored high on EE, while $44.9 \%$ had average levels of DP but a majority (97.7\%) had high levels of reduced PA which was much higher than current results. In a study on 151 community mental health workers in Northern California, it was found that $21-67 \%$ of mental health workers may be experiencing high levels of burnout (Gary et al., 2012). Webster and Hackett, 1999 found in their crosssectional study which was conducted among clinical staff in community mental health agencies, that $54 \%$ had high Emotional Exhaustion and 38\% reported high Depersonalization rates, and high Personal Accomplishment as well. In Census survey study among family physicians done by Joseph et al., 2008, they detected that Emotional 
Exhaustion low, moderate, high were as following respectively $(47.9 \%, 23.2$ $\%, 28.9 \%)$, Depersonalization were (46.3\%,23.1\%,30.6\% respectively), and Personal Accomplishment were (17.4\%, $34.7 \%, 47.9 \%$ respectively).

The current study showed that health care providers in emergency department recorded the highest level of burnout in Depersonalization and Personal Accomplishment sub-scales but in EE subscale the surgical team was highest as shown in Table 4. The study supported the assumption that caring for acutely ill patients may lead to the burnout syndrome due to high mortality rate and decision to withhold or withdraw treatment. These results were in accordance with the findings of Arigoni et al., 2008 who showed high rate of Emotional Exhaustion (29\%, 20\% ), Depersonalization (29\%, $60 \%)$ and Personal Accomplishment (19\%, 37\%) among Critical Care and Emergency health care workers , and $(37 \%, 24 \%)$ respectively for internal medicine.

On the other hand, Crystal et al 2010 found that approximately $82 \%$ of emergency room nurses had moderate to high levels of burnout. Differences between emergency nurses and those working in nephrology and dermatology on the subscales for burnout did not reach the level of statistical significance. However, the intensive care nurses demonstrated a higher risk for burnout.

In the current study, nurses experienced high EE compared with of physicians, for the DP subscale, nearly both physicians and nurses experienced the same levels of scores, and both physicians and nurses experienced highly reduced feelings of PA (Table 4) A cross-sectional study which was conducted at 2012 to 2013 in the emergency hospital of University of Tanta revealed nearly the same results as the nurses experienced high EE which was $(52.8 \%)$ compared with $39.7 \%$ of physicians. But for the DP subscale was lower than current result as $48.2 \%$ of nurses had low scores and $44.4 \%$ moderate scores, compared with $31.8 \%$ and $45.6 \%$ of physicians respectively. PA score was much higher than current result, as nearly all physicians (99.2\%) experienced highly reduced feelings of personal accomplishment and the rate was slightly lower among nurses (96.5\%) (Abd EL- Fatah et al., 2015).

Linear regression analyses were conducted to determine whether risk factors previously described in the 
literature were predictors of burnout in this sample which was nearly agreed with Kara et al., 2011 who reported that regression results indicated that being female significantly predictedEmotional Exhaustion and older respondents' physicians reported significantly higher Personal Accomplishment.

\section{Conclusion and Recommendations}

The present study concludes high prevalence of BOS among HCPs. We recommend carrying out three levels of change to reduce the risk of burnout: (1) modifying the organizational structure and work processes; 2) improving the balance between the organization and the individual HCPs through professional development programs for better adaptation to the work environment; and finding balance in the life.

\section{Conflicts of interest}

The authors declared no conflicts of interest exist.

\section{Funding}

No sources of fund.

\section{Acknowledgment}

We are grateful for all HCWs for their participation in the study. We would like to thank the hospital administrators for their help.

\section{References}

1. Abd EL-Fatah S, El-Sallamy R.M, El-Sherbiny AAM , and Kabbash IA (2015): Burnout among physicians and nursing staff working in the emergency hospital of Tanta University. Eastern Mediterranean Health Journal; 21 (12): 907-912.

2. Abdulla L, Al-Qahtani D.M, and Al-Kuwari MG (2011): Prevalence and determinants of burnout syndrome among primary healthcare physicians in Qatar. South African Family Practice Journal; 53(4):380-3.

3. Arigoni F, Bovier PA, Mermillod B, Waltz P, and Sappino AP (2008): Prevalence of burnout among Swiss cancer clinicians, pediatricians and general practitioners. Support Care Cancer; 17(1):75-81.

4. Crystal H, Janet C, David RJ, Margaret AW and Elaine R (2010): Compassion Satisfaction, Burnout, and Compassion Fatigue Among Emergency Nurses Compared With Nurses in Other Selected Inpatient Specialties. Journal of Emergency Nursing; 36(5): 420-427.

5. De Oliveira GS, Ahmed S, Stock MC, Harter RL, Almeida PC, et al. ( 2010 ): High incidence of burnout in academic chairpersons of anesthesiology: should we be taken better care of our leaders? Anesthesiology; 114(1):181-93.

6. Embriaco NL, Azoulay E, Barrau K, Kentish N, Pochard F, et al (2007): High level of burnout in intensivists: prevalence and associated factors. Am J Respir Crit Care Med; 175(7):686-92 .

7. Gary M, Michelle P and Salyers M (2012): Burnout in Mental Health Services: A Review of the Problem and Its Remediation. Adm Policy Ment Health; 39(5): 341-352. doi:10.1007/ s10488-011-0352-1.

8. Joseph L, Moira S and Judith BB (2008): Stress, burnout, and strategies for reducing them. Can Fam Physician; 54:234-5.

9. Kara K, Ballenger B, Kimberly J, Schmitz MS, John A, et al (2011): Predictors of Burnout Among Military Mental Health Providers. Military Medicine; 176 (3):3-253. 
10. McGrath A, Reid N and Boore J (1989): Occupational stress in nursing. International Journal of Nursing Studies; 26: 359-368.

11. Maslach C, Jackson S and Leiter M (1986): Maslach Burnout Inventory Manual, 2nd ed. Palo Alto: Consulting Psychologists Press; 1986.

12. Pavlakis A, Raftopoulos V and Theodorou M (2010): Burnout syndrome in Cypriot physiotherapists: a national survey. BMC
Health Serv Res; 10:63. PMID:20222948

13. Sr̈gaard KW, Ryan P, Hill R and Dawson I (2007): Sources of stress and burnout in acute psychiatric care: inpatient vs. community staff. Soc Psychiatry Psychiatr Epidemiol; 42(10):794-802. PMID: 17700977

14. Webster L and Hackett RK (1999): Burnout and leadership in community mental health systems. Adm Policy Ment Health; 26(6):387-399. [PubMed: 10615741]. 